\title{
A multi-criteria optimization and decision-making approach for improvement of food engineering processes
}

\author{
Abakarov, A. ${ }^{\mathrm{a}, \mathrm{b}^{*}}$, Sushkov, Yu. ${ }^{\mathrm{c}}$, And Mascheroni, R.H. ${ }^{\mathrm{d}}$ \\ ${ }^{a}$ Higher Technical School of Agricultural Engineering, Technical University of Madrid, Spain. \\ ${ }^{\mathrm{b}}$ Institute of canning and vegetable drying industry (VNIIKOP), Moscow, Russia. \\ ${ }^{c}$ Mathematics Department, St. Petersburg State University, Saint-Petersburg, Russia. \\ ${ }^{d}$ CIDCA (CONICET - UNLP) and MODIAL Facultad de Ingeniería, UNLP, 47 and 116, 1900 La Plata, \\ Argentina. \\ * Corresponding author \\ alik.abakarov@upm.es \\ TEL: +79166805796 \\ FAX: +34-91 3365845
}

Received: 13 February 2012; Published online: 18 April 2013

\begin{abstract}
The objective of this study was to propose a multi-criteria optimization and decision-making technique to solve food engineering problems. This technique was demonstrated using experimental data obtained on osmotic dehydration of carrot cubes in a sodium chloride solution. The Aggregating Functions Approach, the Adaptive Random Search Algorithm, and the Penalty Functions Approach were used in this study to compute the initial set of non-dominated or Pareto-optimal solutions. Multiple non-linear regression analysis was performed on a set of experimental data in order to obtain particular multi-objective functions (responses), namely water loss, solute gain, rehydration ratio, three different colour criteria of rehydrated product, and sensory evaluation (organoleptic quality). Two multi-criteria decision-making approaches, the Analytic Hierarchy Process (AHP) and the Tabular Method (TM), were used simultaneously to choose the best alternative among the set of non-dominated solutions. The multi-criteria optimization and decision-making technique proposed in this study can facilitate the assessment of criteria weights, giving rise to a fairer, more consistent, and adequate final compromised solution or food process. This technique can be useful to food scientists in research and education, as well as to engineers involved in the improvement of a variety of food engineering processes.
\end{abstract}

Keywords: multi-objective optimization, multi-criteria decision-making, osmotic dehydration, adaptive random search, aggregating functions, sophisticated software.

\section{Introduction}

In industrial food processes, several response variables or particular objectives can describe quality characteristics of the final product. These different particular objectives may be conflicting, non-conflicting, or partially conflicting (Seng \& Rangaiah, 2008). Conflicting objectives refer to situations in which a particular objective can only be improved by compromising the other ob- jectives, whereas non-conflicting objectives share a similar optimal point. Finally, partially conflicting objectives refer to cases in which the objectives are conflicting only within a particular range of values. It should be noted that there are various definitions of the term "conflicting" in the literature dealing with multi-objective optimization and decision-making (Brockhoff \& Zitzler, 2009). For example, Deb (2001) defines a set 
of objectives as conflicting if no one solution simultaneously achieves the optimal value for each criterion; otherwise the set is non-conflicting. Deb and Saxena (2006), on the other hand, consider that the pair-wise correlation between objectives is the indicator of conflict between them. Tan, Khor, and Lee (2005) presented a refinement of this definition in which a conflict denotes the existence of incomparable solutions in the search space. A similar notion of conflict has been suggested by Purshouse and Fleming (2003), in which conflict is defined as a binary relation between single objectives. Multi-objective optimization (MOO) of a problem, with conflicting or partially conflicting objectives, yields not just one but many optimal solutions. These solutions are called non-dominated or Pareto-optimal solutions (Steuer, 1985). Each of the Paretooptimal solutions can be considered as a final "compromise" solution of multi-objective optimization problems because it has no a priori advantage over other Pareto-optimal solutions. Therefore, an important task in multi-objective optimization is to identify a representative subset of the Pareto-optimal solutions, since the initial set of multi-criteria alternatives can be reduced significantly. The following approaches have been successfully used over the last few decades to compute Pareto-optimal solutions:

1. aggregating functions approach, that consists of transforming the MOO problems into a single global optimization problem such that their optimal solutions for several chosen parameters yield one Pareto-optimal point (Marler \& Arora, 2004);

2. Parameter Space Investigation (PSI) method, which is based on the search of the parallelepiped with points of uniformly distributed sequences ( $L P_{\tau}$ sequences) (Statnikov \& Matusov, 1995; Statnikov, Bordetsky, \& Statnikov, 2005);

3. multi-objective evolutionary algorithms, which are based on the utilization of genetic algorithms (Siinivas \& Deb, 1994; Deb, 2001; Zitzler \& Thiele, 1999; Joshua \& David, 2000).

The construction of the set of Pareto-optimal solutions is of primary importance in the MOO.
However, once the Pareto-optimal solutions are found, a further step is required, known as multicriteria decision-making analysis (MCDA); this involves further considerations in order to choose a final solution. MCDA is an umbrella term used to describe the collection of formal approaches that use an explicit account of multiple criteria in order to help individuals or groups explore decisions that matter. Decisions matter when the level of conflict between criteria, or between different stakeholders regarding what criteria are relevant, assumes such proportions that decisionmaking based on one's intuitive "gut-feeling" is no longer satisfactory (Belton \& Stewart, 2002). Within the multi-criteria analysis theory the two following mainstreams exist (Treitz, Schollenberger, Schrader, Geldermann, \& Rentz, 2005; Vassilev, Genova, \& Vassileva, 2005; Belton \& Stewart, 2002):

1. the "classical" approaches, which are based on the assumption that clear judgements exist about utility values of the attributes and their weightings, which have to be formalized within the multi-criteria technique. Examples are the multi attribute utility (value) theory methods (Keeney \& Raiffa, 1993), UTA method (Beuthe \& Scannella, 2001), MACBETH method (Costa \& Chagas, 2004), direct weighting method (Von Winterfeldt \& Edwards, 1986) and AHP weighting methods (Saaty, 1990);

2. the outranking methods are based on the assumption that there exists limited comparability among the alternatives. Examples are the ELECTRE, PROMETHEE and TACTIC methods (Figueira, Greco, \& Ehrgott, 2005; Vansnick, 1986).

Multi-objective optimization has been successfully implemented in the analysis of the following kinds of food processes: thermal sterilization of packaged food (Erdogdu, 2003; Sendín, Alonso, \& Banga, 2010; Abakarov, Sushkov, Almonacid, \& Simpson, 2009); evaporator systems (Seng \& Rangaiah, 2008; Sharma, Rangaiah, \& Cheah, 2012), roasting (Goñi \& Salvadori, 2011; Goñi \& Salvadori, 2012), drying (Kiranoudis \& Markatos, 2000), baking (Hadiyanto, Boom, Van

IJFS | April 2013 Volume 2 |pages 1-21 
Straten, Van Boxtel, \& Esveld, 2009), minimization of the food safety risk (Thakur, Wang, \& Hurburgh, 2010). The most interesting applications of multi-objective optimization in the food industry were described in Seng and Rangaiah (2008). The use of multi-criteria decision-making analysishas also been suggested in the area of food science (Bevilacqua, D'Amore, \& Polonara, 2004; Xu, Shiying, Xiufang, \& Da-Wen, 2001; Fogliatto \& Albin, 2003). In industrial osmotic dehydration processes, several responses or particular objective functions describe the quality characteristics of the final products (BarbosaCánovas \& Vega-Mercado, 1996). One of the critical points in this case is the conflicting nature of these responses. For example, the ratio of water loss to solid gain depends on both the solute concentration and its molecular weight. By using highly concentrated solutions, a considerable product weight loss can be achieved along with a low solute gain (Eren \& Kaymak-Ertekin, 2007). In contrast, at low solute concentrations in the dehydrating solution, solute gain by the product is favored, and, likewise, the use of solutes of high molecular weight favours water loss at the expense of solid gain (Eren \& KaymakErtekin, 2007). In such situations, each response can have a different optimum point, in other words, no levels exist that are concurrently optimal for all responses. These situations can be carried out with the multi-objective and decision making approaches. The most widely used multiobjective optimization approach for the optimization of osmotic dehydration processes is the Response Surface Methodology coupled with the Desirability Functions Approach (DFA)wherein equal weights or importance are defined for all responses (Singh, Paramjit, Nanda, \& Bera, 2008; Erdogdu, F, 2009; Noshad, Mohebbi, Shahidi, \& Mortazavi, 2012). DFA is a nonlinear scalarization technique that converts a multi-objective problem into a maximization problem with a single objective which is the geometrical mean of the individual desirability values of different objectives (Derringer \& Suich, 1980). In order to use the DFA, a decision maker should assess not only the bounds of a response and the desirability function shape (e.g. linear, convex, or concave), but also the relative weights or importance of each response. Thus, knowing the true meaning and validity of these weights prior to solving the multiple response optimization problem is crucial in order to avoid the improper use of the DFA. In other words, the DFA emphasizes the need to introduce relative importance weights, but does so without any discussion of how such value judgments should be carried out. For the case when all relative weights are equal, the implementation of the DFA cannot always guarantee a consistent and adequate final solution. Thus, additional methods must be simultaneously used with the DFA when assessing these complex tasks. In order to avoid this disadvantage, the desirability functions have been coupled with different expert identified constraints, including maximizing moisture loss, weight reduction, and/or minimizing solid gain (Azarpazhooh \& Ramaswamy, 2012). Significant developments in the process of osmotic dehydration reveal the importance of the use of this effective preprocessing technique as a unit operation in the food processing industry (Azarpazhooh \& Ramaswamy, 2012). Nevertheless, there is still a problem with the optimization of this multi-objective process in economic and final product quality terms. Therefore, in this work, which is an extension of that originally presented by Abakarov (2011), we propose an alternative technique to solve the multi-criteria optimization and decision-making problems arising in the field of food engineering. The proposed technique has been demonstrated using experimental data collected on osmotic dehydration of carrot cubes in a sodium chloride solution.

\section{Materials and Methods}

\subsection{Pareto-optimal solutions}

A general multi-objective optimization problem can be formulated as follows (Abakarov et al., 2009):

$$
\Phi(x)=\left\langle f_{1}(x), f_{2}(x), \ldots, f_{l}(x)\right\rangle \rightarrow \rightarrow_{x \in X}^{\min }
$$

where: $X \subset R^{n}$ is a non-empty set of feasible decisions (a proper subset of $R^{n}$ ), $x=$ $\left\langle x_{1}, x_{2}, \ldots, x_{n}\right\rangle \in X$ is a real $n$-vector decision variable, and $f_{i}=R^{n} \rightarrow R$ are particular multiobjective functions. We assume that all of the constraints are included in the particular objec- 
tive functions (1) by utilizing the penalty functions. If no vector $x^{*}=\left\langle x_{1}^{*}, x_{2}^{*}, \ldots, x_{n}^{*}\right\rangle \in X$ exists such that $x^{*}=\underset{x \in X}{\operatorname{argmin}} f_{i}(x), \forall i \in 1: l$, that is if no vector exists that is optimal for all objectives concurrently, then there is no unique optimal solution, and a concept of acceptable solutions is needed. The subset $W P(X)=\left\{x^{p} \in X\right.$ : such that there does not exist an $x \in X$ with $\left.f_{i}(x) \leq f_{i}\left(x^{p}\right), \forall i \in 1: l\right\}$ is called the set of Pareto-optimal solutions of the problem (1). Pareto-optimal solutions are the only acceptable solutions of a multi-objective optimization problem, since any other solution can be improved. Pareto-optimal solutions are also known as nondominated or efficient solutions. The space in $E^{1}$ formed by the points of the set $P(X)=\{x \mid$ $x \in W P(X)\}$ is called a Pareto optimal frontier or front. Figure 1 provides a visualization of the definitions made for the two-dimensional MOO problem (1) and two particular objectives (Abakarov et al., 2009). The utopia vector $\Phi^{*}=$ $\left\langle f_{1}\left(x^{*}\right), f_{2}\left(x^{*}\right), \ldots, f_{l}\left(x^{*}\right)\right\rangle$ is the vector containing the individual global minima of the particular objectives.

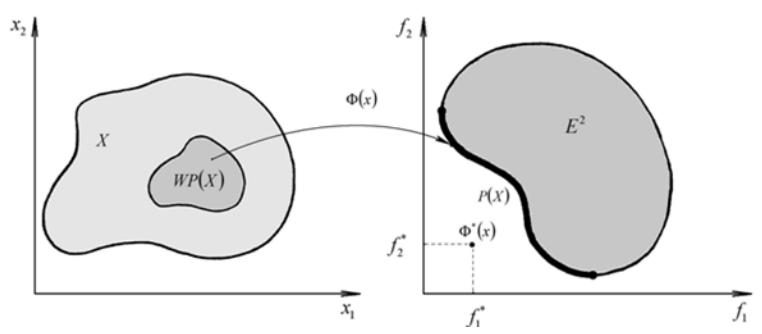

Figure 1: Visualization of the definitions made for the two-dimensional MOO problem (1) and two particular objectives (Abakarov et al., 2009).

\subsection{Approach to compute Pareto-optimal solutions}

The computation of Pareto-optimal solutions is based on optimizing the following aggregating functions by using the adaptive random search algorithm (Abakarov et al., 2009). Weighted minmax aggregating function (Steuer, 1985; Belton \& Stewart, 2002)

$$
\Phi(x)=\min _{x \in X} \max _{i \in 1: l} \lambda_{i} f_{i}(x)
$$

$$
\sum_{i=1}^{l} \lambda_{i}=1 \lambda_{i} \geq 0
$$

Linear weighted sum aggregating function (Steuer, 1985; Belton \& Stewart, 2002)

$$
\begin{gathered}
\Phi(x)=\sum_{i=1}^{l} \lambda_{i} f_{i}(x) \rightarrow \min _{x \in X} \\
\sum_{i=1}^{l} \lambda_{i}=1 \lambda_{i} \geq 0
\end{gathered}
$$

where $\lambda_{i}$ is the weight used for the $i$-th particular objective function $f_{i}(x)$. The penalty aggregating function (Abakarov et al., 2009)

$$
\Phi(x)=f_{k}\left(x^{s}\right)+\sum_{j=1}^{l} P_{j}\left(x^{s}\right) \rightarrow \min _{x \in X}
$$

where $k, k \in 1: l$ is a randomly chosen number at the first step of an adaptive random search of a particular objective function, $f_{k}\left(x^{s}\right)$ is the value of the $k$-th particular objective function at step $s$ of the adaptive random search algorithm, and $P_{j}\left(x^{s}\right)$ is the penalty function of the $j$-th particular objective function computed at step of the adaptive random search algorithm. The following formula is used to compute the penalties $P_{j}\left(x^{s}\right), j \in 1: l$ :

$$
\begin{array}{r}
P_{j}\left(x^{s}\right)=A\left(\left|f_{j}\left(x^{s}\right)-f_{j}\left(x^{s-1}\right)\right|\right. \\
\left.+f_{j}\left(x^{s}\right)-f_{j}\left(x^{s-1}\right)\right)
\end{array}
$$

where $A$ is a sufficiently large number.

\subsection{Penalty Functions Approach}

A Penalty Functions Approach can be coupled with the Aggregating Functions Approach in order to compute the Pareto-optimal solutions, which can satisfy some additional constraints related to the decision maker's preferences. For the following constraint,

$$
a_{j} \leq f_{j}(x) \leq b_{j}
$$

where $a_{j}$ and $b_{j}$ are functions dependent on vector $x$ and $f_{j}(x)$ is a particular objective function, or constant value. In order to satisfy the

IJFS | April 2013 | Volume 2 | pages 1-21 
constraint (6), the following penalty function is proposed (Abakarov \& Nuñez, 2012):

$$
\Theta_{j}=A\left(\left|a_{j}-f_{j}(x)\right|+\left|b_{j}-f_{j}(x)\right|-\left(b_{j}-a_{j}\right)\right)
$$

Where A is a sufficiently large number. Thus, the following optimization problem is solved in this case:

$$
\Phi^{\Theta}(x)=\Phi(x)+\Theta_{j}
$$

where $\Phi(x)$ is any of the above aggregating functions: equations (2), (3) or (4). For a candidate solution with no limit violation, the penalty function (7) becomes zero and the merit function (8) is equal to the objective function value. On the other hand, if there is any violation in the lower or upper limit of the decision variables, a corresponding penalty value is added to the objective function based on the amount of the violation. Since this penalty value is proportional to the distance to the feasible domain, the adaptive random search algorithm can find multi-objective solutions that satisfy all the given constraints.

\subsection{Desirability Functions Approach}

In a multi-response optimization problem, a response $Y_{k}(x), k \in 1: K$, is a function $Y_{k}$ : $R^{n} \rightarrow R$ of vector of independent variables $x=\left(x_{1}, x_{2}, \ldots, x_{n}\right)$ (Del Castillo, 2007). An individual desirability function $d_{k}\left(Y_{k}(x)\right)$ scales a response into the interval $[0,1]$, i.e., $d_{k}: R \rightarrow$ $[0,1], K \in 1: K$, which means that the function d becomes 0 for completely undesirable values of response, and it becomes 1 for totally desirable or ideal values of the response. The individual desirabilities are then combined using the geometric mean, which gives the overall desirability or desirability index (DI) value:

$$
D=\left(\prod_{k=1}^{k} d_{k}\left(Y_{k}(x)\right)\right)^{\frac{1}{k}}
$$

Depending on whether a particular response $Y_{k}(x)$ (is to be maximized, minimized, or assigned a target value, different desirability functions $d_{k}\left(Y_{k}(x)\right)$ can be used (Del Castillo, 2007). A useful class of desirability functions was proposed by Derringer and Suich (1980). When the importance of individual desirability functions may differ in computing the overall desirability functions, a weighting strategy is possible (Derringer, 1994):

$$
D=\left(\prod_{k=1}^{k} d_{k}\left(Y_{k}(x)^{w_{k}}\right)\right)^{\frac{1}{w_{k}}}
$$

where $w_{k}-\sum_{k=1}^{k} w_{k}$. These weights can be specified by a decision maker next to the shapes of the curves of desirability functions, taking into account relative importance of the product, process and system responses with respect to each other (Derringer \& Suich, 1980; Derringer, 1994). Usually these weights are not easy to determine and on the other hand there is no general guideline to do it. The following theorem gives a relationship between the DFA and the aggregating function approach (Mehnen \& Trautmann, 2006).

Theorem 1. Let a process characterized by quality criteria $Y_{k}(x), k \in 1: K$, and influence factors $x_{i}, i \in 1: n$, be given. Optimal influence factor levels $x^{\text {opt }}=\left(x_{1}^{\text {opt }}, x_{2}^{\text {opt }}, \ldots, x_{n}^{\text {opt }}\right)$ are assumed to have been determined based on desirability functions $d_{k}\left(Y_{k}(x)\right)$ and the computed by equation (9). Then it holds that $x^{\text {opt }}$ is Paretooptimal.

The equation (10) used for computing a weighted overall desirability functions is known in MOO theory as a particular case of the weighted product aggregation function used in (Marler \& Arora, 2004). Therefore, the DFA can be considered as a particular case of used in this study aggregating functions approach.

\subsection{Adaptive Random Search Algorithm}

The adaptive random search method belongs to a specific class of global stochastic optimization algorithms (Zhigljavsky \& Zilinskas, 2008). This class of algorithms is based on generating the decision variables from a given probability distribution, and the term "adaptive" consists of modifications to the probability distribution used in the searching process, which, throughout the whole search process, locates global solution. A discrete analogue of the normal distribution - the 
6|Abakarov et al.

pedestal probability distribution - is included in the adaptive random search algorithm (Abakarov \& Nuñez, 2012). During the search process, a random search generates random vector values $x^{0}, x^{1}, \ldots, x^{s}$; calculates the optimization problem $\Phi(x) \rightarrow \min _{x \in X}$; accumulates information about the solved problem; and transforms the pedestal frequency distribution according to the computations performed. Transformations consist of reducing the deviation of the pedestal distribution around the mean (or the center point $\left.x_{i}^{0}, i \in 1: n\right)$, which is the current best solution $x^{0} \in X, \Phi\left(x^{0}\right)<\Phi\left(x^{j}\right), \forall j \in 1: s$.

\subsection{Analytic Hierarchy Process}

The Analytic Hierarchy Process (AHP) proposed by Saaty (1990) is a powerful and flexible multicriteria decision-making approach for dealing with complex problems where both qualitative and quantitative aspects need to be considered. The AHP helps analysts to organize the critical aspects of a problem into a hierarchy rather like a family tree. By reducing complex decisions to a series of simple comparisons and rankings, then synthesizing the results, the AHP not only helps analysts to arrive at the best decision, but also provides a clear rationale for the choices that are made. AHP simplifies complex problems by arranging the decision factors in a hierarchical structure (Bevilacqua et al., 2004). The AHP method is implemented through the following steps

1. Define decision criteria in the form of a hierarchy of objectives. The hierarchy is structured on different levels: from the top (i.e. the overall objective), through intermediate levels (the criteria and sub-criteria on which subsequent levels depend), to the lowest level (i.e. the alternatives);

2. Construct a set of square pair-wise comparison matrices for each of the lower levels with one matrix for each element in the level immediately above. For this purpose, the AHP uses simple pair-wise comparisons to determine weights and ratings so that the analyst can concentrate on just two factors at a time. Verbal judgements are then translated into a score using discrete 9-point scales;

3. The hierarchy synthesis function is used to weight the eigenvectors by the weights of the criteria and the sum is taken over all weighted eigenvector entries corresponding to those in the next lower level of the hierarchy.

One of the strengths of the AHP approach is that it allows decision-makers to specify their preferences using the verbal scale shown in Table 1 (Grandzol, 2005).

\subsection{Tabular Method}

The Tabular Method (TM) (Sushkov, 1984) is a flexible multi-criteria decision-making approach that can be effectively used for quickly selecting the best alternatives from a range of initial alternatives. The car selection problem will be considered here as an example in order to concretize the Tabular Method's basic idea. TM consists of the following steps:

1. A table is created wherein the column number $\mathrm{k}$ is related to the decision criterion $k, k \in 1: K$, and the row number $m$ is related to the alternative involved in the decision-making process, $m, m \in 1: M$. Let $\delta[m, k]$ be a value in the table at row $m$ and column $k$. Table 2 contains initial data prepared for the osmotic dehydration conditions selection problem. The criteria used to select the preferred conditions are the following: water loss $(\%)$, solute gain (\%) and weight reduction (\%).

2. For each column (criterion) of the table, the alternatives are arranged in order from the most to the least desirable. In other words, if responses are to be maximized, the alternatives are arranged in decreasing order, but if the responses are to be minimized, the alternatives are arranged in increasing order. Let $\delta\left[\sigma_{k} m, k\right]$ be a value in the table at row $\mathrm{m}$ and column $\mathrm{k}$ after the preference ordering of the alternatives, where $\sigma_{k}$ is a permutation of the set $\{1,2, \ldots, M\}$. Table 3 shows the initial data arranged in order from the

IJFS | April 2013 | Volume 2 pages 1-21 
Multi-criteria optimization for food engineering $\mid 7$

Table 1: The fundamental scale for pair-wise comparisons used in the AHP approach.

\begin{tabular}{|c|l|}
\hline Intensity of importance & Definition \\
\hline 1 & Equal importance \\
\hline 3 & Moderate importance \\
\hline 5 & Strong importance \\
\hline 7 & Very strong importance \\
\hline 9 & Extreme importance \\
\hline $2,4,6,8$ & For compromises between the above \\
\hline
\end{tabular}

Table 2: Initial table for the osmotic dehydration conditions selection problem*.

\begin{tabular}{|c|c|c|c|}
\hline & \multicolumn{3}{|c|}{ Criteria } \\
\hline $\mathrm{N}$ & Water loss (\%) & Solute gain (\%) & Weight reduction (\%) \\
\hline Process 1 & 28 & 5 & 22 \\
\hline Process 2 & 19 & 2 & 14 \\
\hline Process 3 & 32 & 15 & 17 \\
\hline Process 4 & 18 & 1.5 & 19 \\
\hline Process 5 & 21 & 4 & 20 \\
\hline Process 6 & 25 & 6 & 10 \\
\hline
\end{tabular}

* the criteria used to select the preferred conditions (process) are the following: water loss (\%), solute gain (\%) and weight reduction (\%)

most to the least desirable. Since the lowest solute gain will be the best choice, the values of the second column are arranged in increasing order. The other two columns are arranged in decreasing order, since the higher values of the water loss and weight reduction will be the most desirable ones.

3. Each non-Pareto-optimal alternative is deleted from the table. The alternative (process) number 6 with the criteria values: water loss $=25 \%$, solute gain $=4 \%$, weight reduction $=20 \%$, not a Pareto-optimal one, because it is worse than alternative number 1 on all criteria simultaneously; thus, we delete the data of process conditions number 6 from the table.

4. Constraints are imposed on each of the criteria (columns), namely the worst-case values that are acceptable for each of the criteria. Let $\gamma_{k}, k \in 1: K$, be a worst-case value, acceptable for criterion $\mathrm{k}$, and thus all values of the table that satisfy the constraint $\delta\left[\sigma_{k} m, k\right] \geq \gamma_{k}$, where $\geq$ indicates preference, will be acceptable. Let the worst-case value for the criterion water loss be equal to $21 \%$, which means that the decision-maker or food engineer prefers to have a process with the water loss criterion value higher than $21 \%$. Also, the food engineer prefers a process with the solute gain criterion value below $5 \%$, and with the weight reduction criterion value higher than $19 \%$. Table 4 shows the results after step number 4 . The cells marked in yellow are acceptable for each of the criteria whereas those marked in red are not acceptable.

5. The table is then examined for non-empty sets of solutions (alternatives) that satisfy the imposed constraints. Namely, if there exists such a $m, m \in 1: M$, that for all $k \in 1: K, \delta\left[\sigma_{k} m, k\right] \geq \gamma_{k}$, then the alternative $m$ is a solution of the problem. After examination of Table 4 we can see that the alternative number 1 with the criteria values water loss $=28 \%$, solute gain $=5 \%$ and 
weight reduction $=22 \%$ is the best choice for the food engineer or decision-maker. It is preferable that after step 5 more than one solution is found that satisfies the imposed constraints. In accordance with the number of objects that an average human can hold in working memory (Miller, 1956), we recommend obtaining not more than $7 \pm 2$ final alternatives with the Tabular Method. If after step 5 there is no solution that satisfies all of the constraints, the constraints should then be reduced by the decision-maker.

Table 3: Alternatives of the osmotic dehydration conditions selection problem arranged in order from the most to the least desirable*.

\begin{tabular}{|c|c|c|}
\hline \multicolumn{3}{|c|}{ Criteria } \\
\hline $\begin{array}{c}\text { Water } \\
\text { loss }(\%)\end{array}$ & $\begin{array}{c}\text { Solute } \\
\text { gain (\%) }\end{array}$ & $\begin{array}{c}\text { Weight } \\
\text { reduction }(\%)\end{array}$ \\
\hline 32 & 1.5 & 22 \\
\hline 28 & 2 & 20 \\
\hline 25 & 4 & 19 \\
\hline 21 & 5 & 17 \\
\hline 19 & 6 & 14 \\
\hline 18 & 15 & 10 \\
\hline
\end{tabular}

* since the lowest solute gain will be the best choice, the values of the second column are arranged in increasing order; the other two columns are arranged in decreasing order, since the higher values of the water loss and weight reduction will be the most desirable ones.

\subsection{Decision making approach}

The decision-making approach proposed in this study is based on the consecutive utilization of the TM and AHP methods for a given set of Pareto-optimal solutions. It is well known that a major drawback of AHP is that highdimensional decision-making problems produce a large number of AHP pair-wise comparisons which are needed to obtain the final solution (Carmone, Kara, \& Zanakis, 1997). In addition, it is well established that even under the best circumstances, the respondent in a very long interview is likely to suffer from information overload; thus, a large number of pair-wise comparisons can cause information overload and con-
Table 4: Results after step 4 of the Tabular Method*.

\begin{tabular}{|c|c|c|}
\hline \multicolumn{3}{|c|}{ Criteria } \\
\hline $\begin{array}{c}\text { Water } \\
\text { loss }(\%)\end{array}$ & $\begin{array}{c}\text { Solute } \\
\text { gain (\%) }\end{array}$ & $\begin{array}{c}\text { Weight } \\
\text { reduction }(\%)\end{array}$ \\
\hline 32 & 1.5 & 22 \\
\hline 28 & 2 & 19 \\
\hline 21 & 4 & 17 \\
\hline 19 & 5 & 14 \\
\hline 18 & 15 & 10 \\
\hline
\end{tabular}

*the cells marked in yellow are acceptable for each of the criteria whereas those marked in red are not acceptable (the worst-case values for the criteria: water loss, solute gain and weight reduction are equal to $21 \%, 5 \%$ and $19 \%$, respectively).

fused decision-making (Miller, 1956). However, when there are only a few levels and sublevels, the AHP becomes a powerful tool that can be successfully applied in a straightforward manner to derive the weights or relative preferences of the alternatives. Therefore, in this study, the TM method is first used as the decision-making approach in order to reduce the initial number of the Pareto-optimal solutions or alternatives. The TM method is a relatively easy and fast decisionmaking approach. Once this is carried out, the AHP method is then used to choose the best alternative among the reduced initial set of alternatives. Thus, the whole multi-objective and decision-making approach proposed in this study consists of the following phases:

1. A multiple non-linear regression analysis of the experimental data is performed in order to obtain the mathematical equations for each of the responses or particular multiobjective functions. The following second order polynomial equation can be used to fit the experimental data of each response:

$$
Y_{k}=\beta_{0}^{k}+\sum_{i=1}^{n} \beta_{i}^{k} x_{i}+\sum_{i=1}^{n} \beta_{i i}^{k} x_{i}^{2}+\sum_{i=1}^{n-1} \sum_{j=i+1}^{n} \beta_{i j}^{k} x_{i} x_{j}
$$

where $Y_{k}, k \in 1: K$ is the response variable or particular objective function, $\beta_{0}^{k}, \beta_{i}^{k}, \beta_{i i}^{k}$ and $\beta_{i j}^{k}$ are the regression coefficients, and 
$x_{i}, i \in 1: n$ are the coded or un-coded independent variables.

2. A set of Pareto-optimal solutions is computed for each particular multi-objective function.

3. A decision-making approach based on the AHP and TM methods is performed on the previously obtained set of multi-objective alternatives.

\subsection{Additional analysis underlying the need for a multi-objective optimization and decision making technique}

In order to demonstrate that a multi-objective optimization and decision-making technique was necessary to address the problem described above, the following computations were performed in this study. We create a table in which columns and rows are related to the decision criteria or responses. Let $\delta[m, k]$ be a value at row $m$ and column $k$ in this table, $m, k \in 1: K$, computed as follows:

$$
\delta[m, k]=\frac{\left|y_{m}^{o p t}-y_{m}\left(x_{k}^{*}\right)\right|}{\left(y_{m}^{\max }-y_{m}^{\min }\right)}
$$

where $y_{m}^{\max }$ and $y_{m}^{\min }$ are the minimum and maximum values of the response $y_{m}$, respectively, $y_{m}^{o p t}$ is the optimal value of the response $y_{m}$, $y_{m}\left(x_{k}^{*}\right)$ is the value of the response $y_{m}$ evaluated at point $x_{k}^{*}$, where $x_{k}^{*}$ is the optimal solution of the response $y_{k}$. In other words, the value $\delta[m, k]$ represents the relative loss of response $y_{m}$, when the solution vector $x_{k}^{*}$ of the response $y_{k}$ is used as a solution vector of the response $y_{m}$.

\subsection{Decision-making software packages}

The following two graphic user interface (GUI) software packages were used in this study for decision-making computations Abakarov (2011) 1 :
- "MPRIORITY" a software package based on AHP methodology, and

- "T-CHOICE" a software package based on the Tabular method.

$\mathrm{C}++$ Builder 6.0 was used to design both software packages. These packages assist the user in all phases of the decision-making problem solving process, from model formulation to final report output. The Pareto-optimal solution computations were performed on a notebook with an Intel, Triple-Core, 2.40 GHz CPU with 3.0 GB of RAM. The necessary numerical computation programs were prepared with the Microsoft Visual C++ Express 2010.

\section{Results and Discussion}

\subsection{Multiple non-linear regression analysis and ANOVA}

Table 5 contains experimental data, for an osmotic dehydration process of carrot cubes in a sodium chloride solution, obtained through the Face-Centered Central Composite Design by Singh et al. (2008). The independent process variables were: osmotic solution concentration, process duration and osmotic solution temperature. The low and high levels for these independent variables were taken as: $5-15 \%$ sodium chloride (w/v), 30-50 ${ }^{\circ} \mathrm{C}$ and $90-150$ minutes for osmotic solution concentration, temperature and process time, respectively (Singh et al., 2008). The responses of osmotic dehydration were: water loss (WL), solute gain (SG), rehydration ratio (RR), three different criteria of colour of rehydrated product, namely L-value, a-value, and bvalue, and sensory evaluation (organoleptic quality). The carrot to solution ratio was kept as 1:5 (Singh et al., 2008). In Singh et al. (2008) for each experiment, known weights of carrot cubes of dimension $1 \mathrm{~cm}^{3}(100-120 \mathrm{~g})$ were put in stainless steel containers containing calculated volumes of osmotic solutions of different concentrations preset at the desired temperature in a shaking hot water bath. The temperature was maintained during osmosis. Samples were agitated to reduce mass transfer resistance at the surface of the carrots. During experimentation, it was assumed 
Table 5: Experimental data for an osmotic dehydration process: carrot cubes in a sodium chloride solution as obtained through the Face-Centred Central Composite Design by Singh et al. (2008).

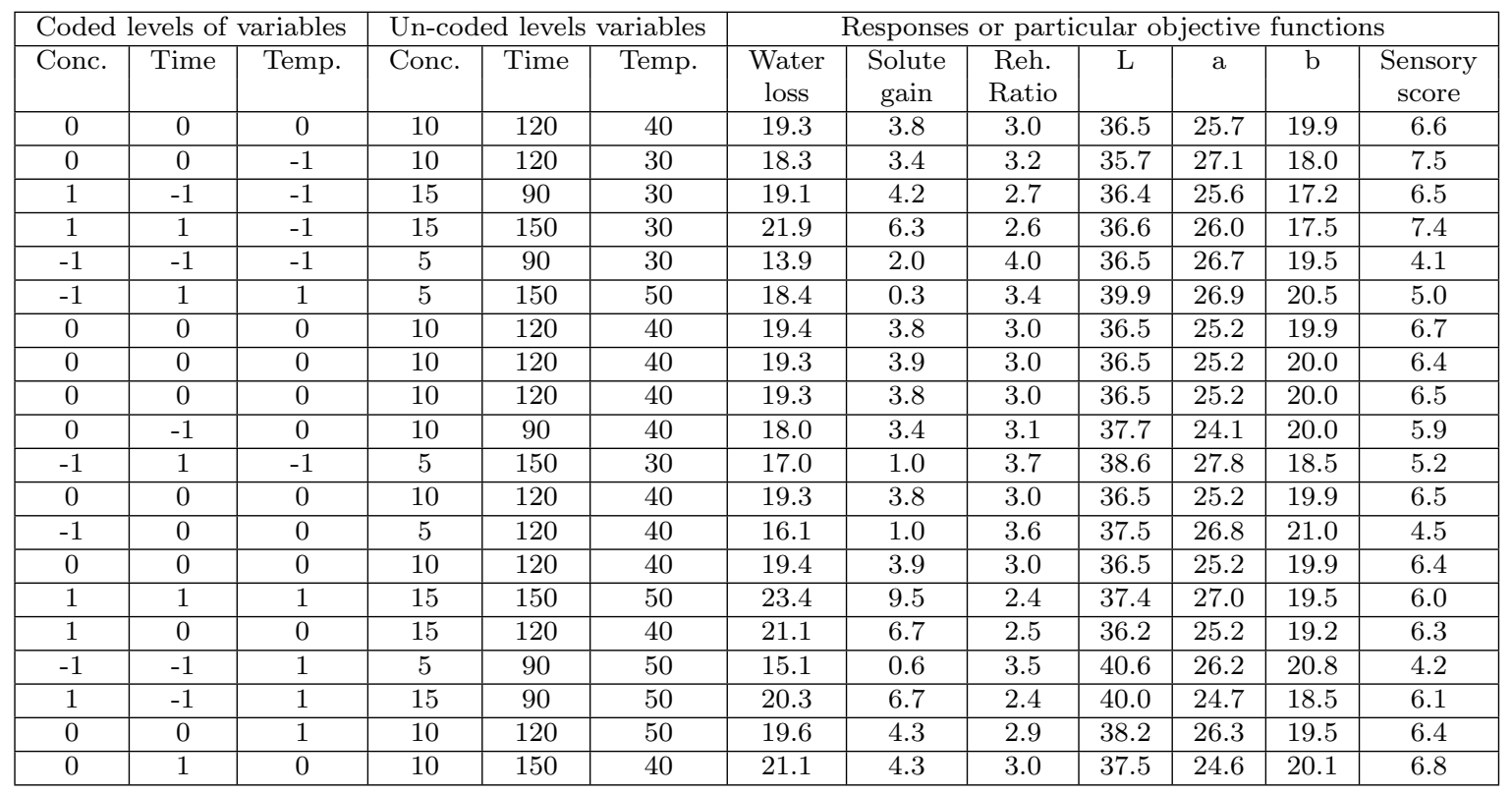

that the amount of solid leaching out of carrots during osmosis was negligible. At the specified times the carrot cubes were removed from the osmotic solutions and rinsed with water to remove surplus solvent adhering to the surfaces. These osmotically dehydrated cubes were then spread on the absorbent paper to remove the free water present on the surface. A proportion of the pretreated carrots (15-20g) was used for determination of dry matter by oven drying. The remaining part of each product sample was dried to a final moisture of $5 \%$ (wet basis) using a hot air drier pre-set at $65^{\circ} \mathrm{C}$ air temperature and $1.5 \mathrm{~m} / \mathrm{s}$ air velocity. The dried samples were cooled in a desiccator containing silica gel for one hr, packed in HDPE (high density polyethylene) bags and kept at ambient temperature for quality analysis. The experiments were conducted randomly to minimize the effects of unexplained variability in the observed responses as a result of external factors. The colour of rehydrated carrot was measured in terms of ' $L$ ', ' $a$ ' and ' $b$ ' values after grinding the samples. Variation in the values of ' $\mathrm{L}$ ', 'a', and 'b' values were observed due to different osmotic pretreatments and also due to the different proportion of xylem (central core of carrot) and phloem (red portion) present in samples. To reduce this variation, observations were recorded in triplicate after proper mixing of ground samples. The colour properties of the rehydrated product were measured using a HunterLab MiniScan XE Plus Colourimeter (U.S.A.). The ground material of rehydrated carrot cubes was completely filled into a plane Petri dish. In Hunter scale "L" varies from 0 (darkness) to 100 (whiteness). The chromatic portion of the solid is defined by: +a (red); -a (green); +b (yellow); -b(blue). Organoleptic quality of dried carrot cubes was determined with the help of a tenmember consumer panel using a 9-point hedonic scale following standard procedures (Singh et al., 2008). The aspects considered for rehydrated carrots were colour, appearance, taste, flavour, and overall acceptability. The average scores of all 10 panelists were computed for different characteristics (Singh et al., 2008). Multiple non-linear regression analysis and ANOVA were conducted to fit a second-order polynomial 
model (11) to the experimental data presented in Table 5, and to determine significant effects of process variables on each response using the MatLab Statistic Toolbox (MatLab, version 7.10.0, R2010a). Thus, regression coefficients of the proposed models and statistical significance of all main effects for each response were computed, and non significant effects $(\mathrm{p}>0.05)$ were removed from the model. ANOVA showed that the lack of fit was not significant for all response surface models at the $95 \%$ confidence level. Table 6 contains the coefficients of the regression model (11) computed for all responses. These results agree well with those originally reported by Singh et al. (2008).

\subsection{Additional analysis underlying the need for multi-objective optimization and decision making technique}

In Singh et al. (2008) the optimization of the osmotic dehydration process was aimed at finding the levels of independent variables that will give maximum possible water loss, rehydration ratio, "L-value", "a-value", sensory score, and lowest solute gain and "b-value" of colour. Table 7 presents information about the optimal levels and values of each response that were found by the adaptive random search algorithm. Table 7 shows that each response has a different optimum point, in other words, no combination of factors/levels exist, that is concurrently optimal for all responses. In order to show the difference between the optimal solutions in Table 7, the additional computations based on equation (12) were performed (see Table 8 ). Table 8 shows that any vector $x_{k}^{*}=\underset{x \in X}{\arg \text { opt }} y_{k}(x), k \in 1: K$, taken as the solution vector for all responses, gives a significant loss for each of the responses. In addition, the average loss for all responses does not fall below $50 \%$.

Table 9 shows the pair-wise correlation of the responses. It can be observed from Table 9 that no strongly correlated responses exist, thus, all responses are in conflict with each other. The experimental data presented in Table 5 above and the subsequent computations show that a multi- objective optimization and decision-making technique is needed for the optimization of osmotic dehydration processes.

\subsection{Computation of Pareto-optimal solutions in the final product}

The distributions of 1000 Pareto-optimal frontier points over the codomains of each response were computed using the aggregating functions (2), (3), and (4), respectively. The results suggest that for problem solving, the penalty aggregating function (4) gives an advantage over the linear weighted sum (3) and the weighted $\min -\max (2)$ functions. The penalty aggregating function (4) demonstrates an ability to generate well-distributed Pareto-optimal frontier points over the Pareto-optimal frontier, which is important for identifying a representative subset of non-dominated frontier solutions. As an example, we show in Figures 2a-2c the distributions of 1000 Pareto-optimal frontier points computed for the WL response by the aggregating functions (2), (3) and (4), respectively. In this study, in order to obtain a representative subset of Pareto-optimal solutions, 100 Pareto-optimal points were computed by each of the aggregating functions (2), (3), and (4). Thus, the obtained subset of 300 Pareto-optimal solutions was used to perform the decision-making approach based on the AHP and TM methods.

\subsection{Decision making analysis of Pareto-optimal alternatives}

Firstly, the TM method was used in order to reduce the initial number of the Pareto-optimal solutions. These computations were performed by the "T-CHOICE" software package. The Paretooptimal frontier point, as published by Singh et al. (2008) through the DFA, was used in this study in order to impose the required constraints on each response. In general, however, this is based on the values and preferences of the decision maker(s). The frontier point, denoted as point A, included the following conditions: 19.0 $\mathrm{g}$ water for every $100 \mathrm{~g}$ of fresh carrot (WL), 
12 |Abakarov et al.

Table 6: Coefficients of the prediction regression model (11) for all responses.

\begin{tabular}{|c|c|c|c|c|c|c|c|}
\hline \multirow{2}{*}{ Source and Term } & \multicolumn{7}{|c|}{ Coefficients } \\
\cline { 2 - 8 } & Water loss & Solute gain & RR & L-value & a-value & b-value & Sensory Score \\
\hline Constant & 295.583 & 110.924 & 67.722 & 416.985 & 398.991 & 6.895 & -2.532 \\
\hline Conc & 108.705 & -0.8272 & -0.1769 & 0.1067 & -0.8802 & -0.5254 & 13.896 \\
\hline Time & -0.03349 & -0.0574 & -0.0113 & -0.1550 & 0.2371 & -0.07532 & 0.0974 \\
\hline Temp & 0.29841 & -0.2188 & -0.058 & 0.1033 & -12.236 & 0.97015 & -0.2389 \\
\hline Conc*Conc & -0.02601 & -0.0003 & 0.0008 & 0.0119 & 0.0273 & 0.0056 & -0.04618 \\
\hline Time*Time & 0.00034 & -0.00001 & 0.00001 & 0.0011 & -0.0011 & 0.00013 & -0.00023 \\
\hline Temp*Temp & -0.00326 & 0.0001 & 0.00027 & 0.004 & 0.0137 & -0.01195 & 0.00395 \\
\hline Conc*Time & -0.00054 & 0.0053 & 0.00024 & -0.0031 & 0.0008 & 0.00209 & -0.00092 \\
\hline Conc*Temp & 0.00009 & 0.0194 & 0.00059 & -0.0025 & 0.0031 & -0.00012 & -0.00425 \\
\hline Time*Temp & 0.00023 & 0.0005 & 0.00011 & 0.0023 & 0.0007 & 0.00056 & -0.00054 \\
\hline
\end{tabular}

Table 7: Optimal levels and values of each response.

\begin{tabular}{|c|c|c|c|c|c|c|c|}
\hline \multirow{2}{*}{ Factor } & \multicolumn{7}{|c|}{ Response } \\
\cline { 2 - 8 } & WL & SG & RR & L-value & a-value & b-value & Sensory score \\
\hline Concentration & 15 & 5 & 5 & 5 & 5 & 15 & 12.17 \\
\hline Time & 150 & 150 & 90 & 90 & 123.33 & 101.515 & 150 \\
\hline Temperature & 50 & 50 & 30 & 50 & 30 & 30 & 30 \\
\hline Objective value & Max: 23.4 & Min: 0.3 & Max: 4.0 & Max: 40.3 & Max: 27.9 & Min: 17.2 & Max: 7.7 \\
\hline
\end{tabular}

Table 8: Relative losses of each response (\%).

\begin{tabular}{|c|c|c|c|c|c|c|c|}
\hline \multirow{2}{*}{ Response } & \multicolumn{7}{|c|}{ Response } \\
\cline { 2 - 8 } & $\begin{array}{c}\text { Water } \\
\text { loss }\end{array}$ & $\begin{array}{c}\text { Solute } \\
\text { gain }\end{array}$ & $\begin{array}{c}\text { Rehydration } \\
\text { ratio }\end{array}$ & $\begin{array}{c}\text { L- } \\
\text { value }\end{array}$ & $\begin{array}{c}\text { a- } \\
\text { value }\end{array}$ & $\begin{array}{c}\text { b- } \\
\text { value }\end{array}$ & $\begin{array}{c}\text { Sensory } \\
\text { score }\end{array}$ \\
\hline Water loss & 0.00 & 51.38 & 99.85 & 87.44 & 84.62 & 41.14 & 24.14 \\
\hline Solute gain & 99.99 & 0.00 & 18.19 & 3.35 & 12.40 & 47.16 & 50.04 \\
\hline Rehydration ratio & 98.10 & 37.69 & 0.00 & 29.36 & 9.30 & 78.30 & 65.96 \\
\hline L-value & 79.20 & 31.05 & 85.76 & 0.00 & 88.93 & 99.99 & 89.14 \\
\hline a-value & 46.62 & 33.80 & 28.51 & 49.48 & 0.00 & 50.03 & 61.34 \\
\hline b-value & 50.08 & 75.93 & 53.73 & 83.97 & 37.70 & 0.00 & 9.56 \\
\hline Sensory score & 44.38 & 73.10 & 92.51 & 88.89 & 69.71 & 22.25 & 0.00 \\
\hline Average loss & 69.73 & 50.49 & 63.09 & 57.08 & 50.44 & 56.48 & 50.03 \\
\hline
\end{tabular}

IJFS | April 2013 | Volume 2 | pages 1-21 
Multi-criteria optimization for food engineering |13

Table 9: The correlation matrix from the data presented in Table 2.

\begin{tabular}{|c|c|c|c|c|c|c|c|}
\hline \multirow{2}{*}{ Response } & \multicolumn{7}{|c|}{ Response } \\
\cline { 2 - 8 } & WL & SG & RR & $\begin{array}{c}\text { L- } \\
\text { value }\end{array}$ & $\begin{array}{c}\text { a- } \\
\text { value }\end{array}$ & $\begin{array}{c}\text { b- } \\
\text { value }\end{array}$ & $\begin{array}{c}\text { Sensory } \\
\text { score }\end{array}$ \\
\hline Water loss & 1.00 & 0.85 & -0.91 & -0.24 & -0.31 & -0.31 & 0.74 \\
\hline Solute gain & & 1.00 & -0.89 & -0.30 & -0.31 & -0.41 & 0.58 \\
\hline Rehydration ratio & & & 1.00 & 0.14 & 0.46 & 0.38 & -0.67 \\
\hline L-value & & & & 1.00 & 0.16 & 0.28 & -0.56 \\
\hline a-value & & & & & 1.00 & -0.13 & -0.39 \\
\hline b-value & & & & & & 1.00 & -0.50 \\
\hline Sensory score & & & & & & & 1.00 \\
\hline
\end{tabular}

$2.5 \mathrm{~g}$ solute for every $100 \mathrm{~g}$ of fresh carrot $(\mathrm{SG})$, 3.4 (RR), L value: 37.8 , a value: 25.6 , b value: 18.1, and sensory score: 6.9. Figure 3 shows the main window of the "T-CHOICE" software with a table that demonstrates the results after applying the TM method to 100 Pareto-optimal frontier points, as computed using the weighted min-max function (2). The columns of this table, from left to right, are Water Loss (WL), Solute Gain (SG), Rehydration Ratio (RR), L-value, avalue, b-value, and Sensory Score, respectively. Each cell in the table corresponds to alternative $m$ (line) and criterion $k$ (column). The values presented are the (estimated) response, and an index (in brackets) that indicates the number of alternative solutions that satisfy the imposed constraints if the cell at row $m$ will be chosen as a worst-case value (constraint) for the criterion $\mathrm{k}$. The alternatives of each column in Figure 3 are arranged in order from most to least desirable. The cells marked in yellow are acceptable for each of the criteria whereas those marked red are not acceptable. For example, the worst-case value for the water loss response (first column in Figure 3 ) is equal to $17.3 \%$; the value of water loss for point $\mathrm{A}$ is $19.0 \%$, but as seen from the table, this value cannot be used as a worst-case value of the water loss response, since there are no solutions that satisfy the imposed constraint. Thus, the value $17.3 \%$ was chosen as the constraint (i.e., $\mathrm{WL} \geq 17.3 \%$ ), which guarantees at least three final Pareto-optimal solutions. For the solute gain response, a worst-case value of $1.8 \%$ is chosen, which is smaller than that for point A. There are three solutions that satisfy the imposed constraint $\mathrm{SG} \leq 1.8 \%$ (Figure 3). Using the same approach, the following constraints were imposed for the other responses: $\mathrm{RR} \geq 3.5$, L-value $\geq$ 36.9 , a-value $\geq 26.4$, b-value $\leq 18.8$, and Sensory Score $\geq 5.7$. Figure 3 shows that there are three solutions that satisfy the imposed constraints, and are shown in Table 10 (numbers 1-3). Thus, the point A solution was improved only for the following responses: solute gain, rehydration ratio, and a-value; this means that point $\mathrm{A}$ is nondominated. Figure 4 shows the results after applying the TM method to 100 Pareto-optimal frontier points, as computed using the weighted sum aggregating function (3). The columns of this table are the same as those in Figure 3,and the alternatives of each column are also arranged in order from most to least desirable. The following constraints were imposed for all responses: $\mathrm{WL} \geq 19.2 \%, \mathrm{SG} \leq 3.0 \%, \mathrm{RR} \geq 3.2, \mathrm{~L}$-value $\geq$ 37.6 , a-value $\geq 26.1$, b-value $\leq 20.2$, and Sensory Score $\geq 5.6$. Figure 4 shows that there are three solutions that satisfy these imposed constraints, and are shown in Table 10 (numbers 4-6).The point A solution was improved for the following responses: water loss, solute gain, Lvalue, and a-value. Figure 5 shows the results after applying the TM method to 100 Paretooptimal frontier points, computed by using the penalty aggregating function (4). The columns and their alternatives are arranged as they are in Figures 3 and 4 . The following constraints were imposed for all responses: WL $\geq 19.3 \%$, SG $\leq$ $3.7 \%, \mathrm{RR} \geq 3.0$, L-value $\geq 36.9$, a-value $\geq 25.2$, 

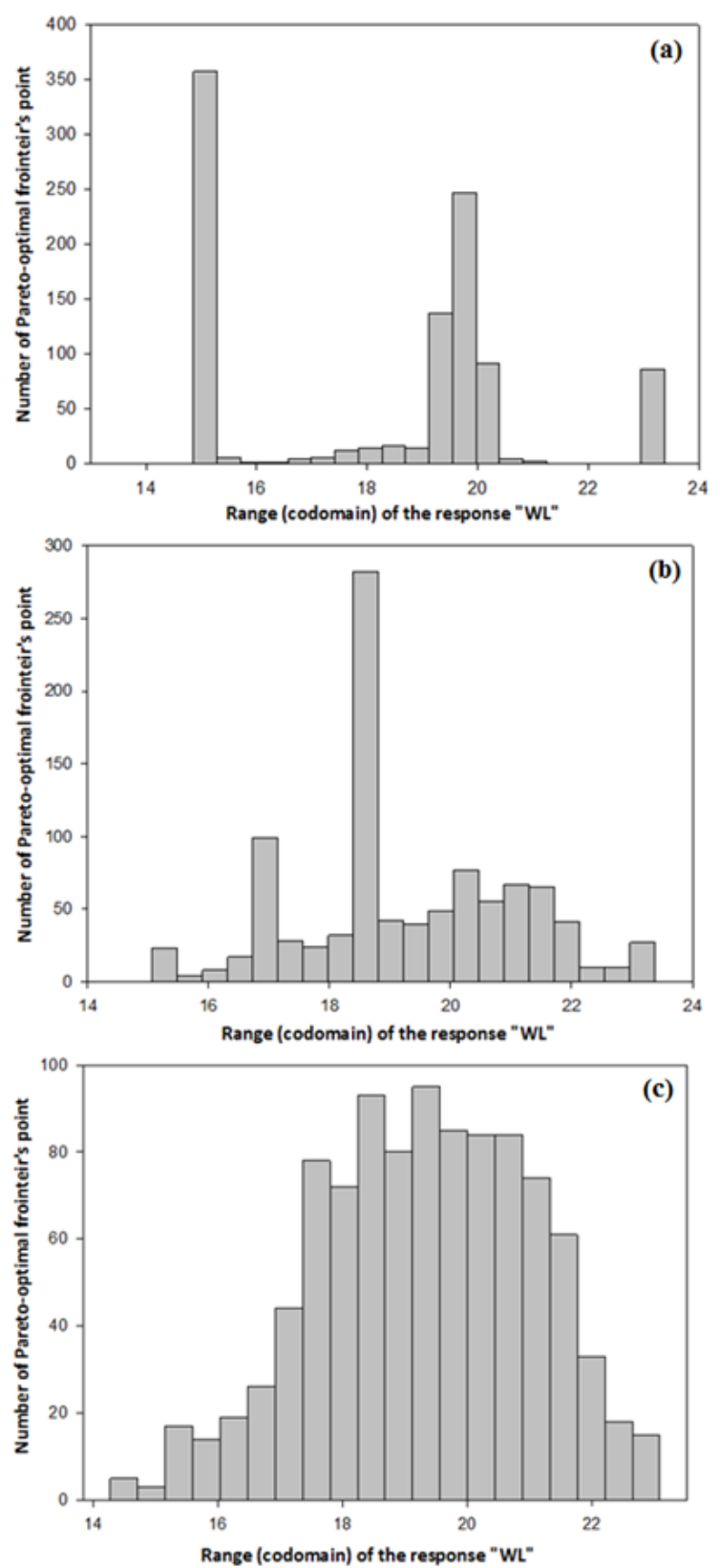

Figure 2: Distributions of 1000 Pareto-optimal frontier points over the codomains of the WL response using the aggregating functions (2), (3) and (4), respectively.

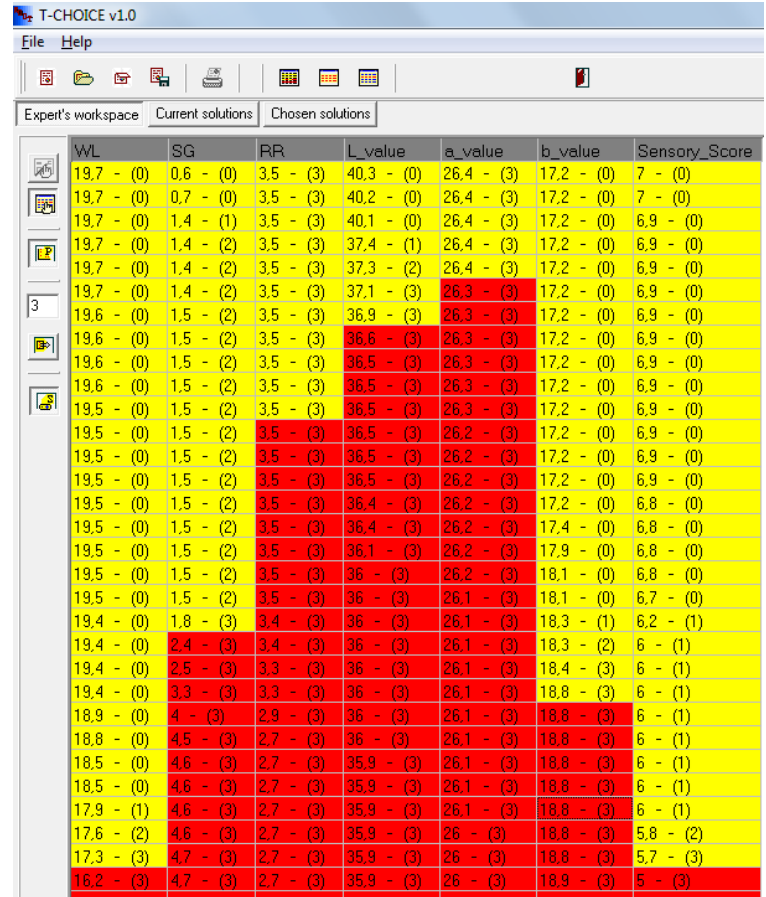

Figure 3: Results after applying the TM method to100 Pareto-optimal frontier points, as computed using the weighted min-max function (2); the cells marked in yellow are acceptable for each of the criteria whereas those marked in red are not acceptable.

b-value $\leq 20.3$, and Sensory Score $\geq 5$.9. Figure 5 shows that there are three solutions that satisfy the imposed constraints, which are shown in Table 10 (numbers 7-9). The point A solution was improved for the following responses: water loss and a-value.Thus, the resulting subset of 300 Pareto-optimal alternatives was reduced to only nine non-dominated alternatives as presented in Table 10. The final stage of the decision-making process consisted of utilizing the AHP approach to choose the preferred alternative among the nine choices obtained. Figure 6 shows the main window of the "MPRIORITY" software with a hierarchy of decisions corresponding to the problem of choosing the most preferred osmotic dehydration process; the main goal is set at the top of the hierarchy, while the decision alternatives (i.e., those presented in Table 10) are at the bottom. The relevant attributes of the deci- 


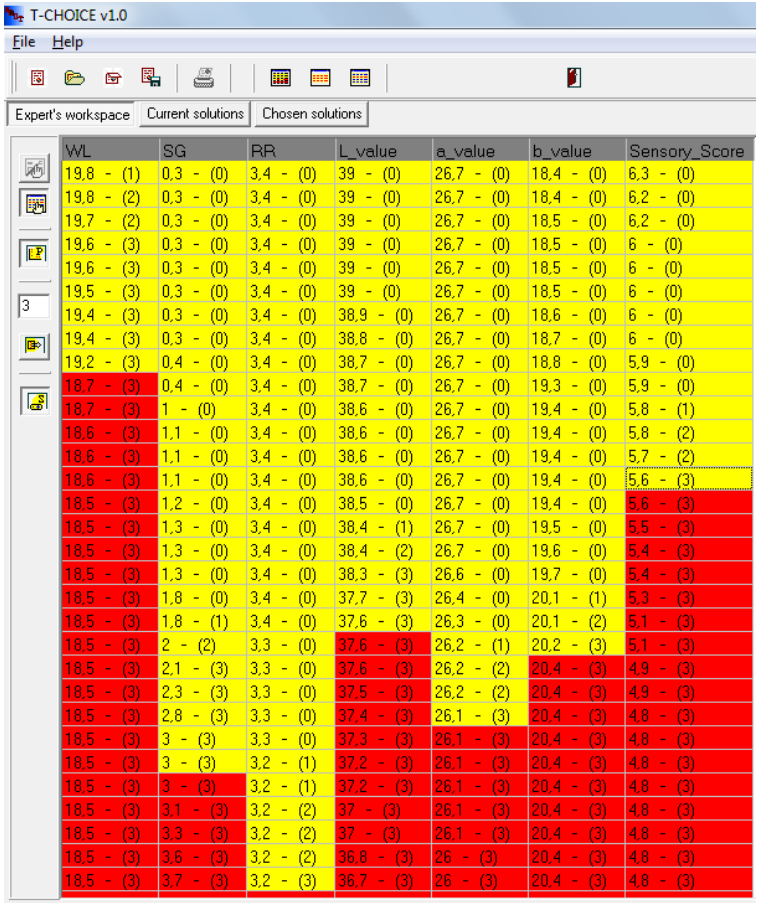

Figure 4: Results after applying the TM method to100 Pareto-optimal frontier points, as computed using the sum aggregating function (3); the cells marked in yellow are acceptable for each of the criteria whereas those marked in red are not acceptable.

sion problem (i.e. water loss, solute gain, rehydration ratio, L-value, a-value, b-value, and sensory score) make up the middle of the hierarchy. A set of pair-wise comparison matrices is developed for every level of the hierarchy as shown in Figure 6. Table 11 shows the results of the pair-wise comparisons for the main criteria with respect to the main goal. We based our comparisons on the recommendations given by Singh et al. (2008). The main criteria are arranged in the following order: sensory score (importance: 0.3284), water loss(importance: 0.199), a-value (importance: 0.1878), L-value (importance: 0.0995), rehydration ratio (importance: 0.085), solute gain(importance:0.0554), and bvalue (importance: 0.0447). Table 12 shows the weights computed for each alternative with respect to each main criterion and final AHP priority-weights vector. The alternative 3 with

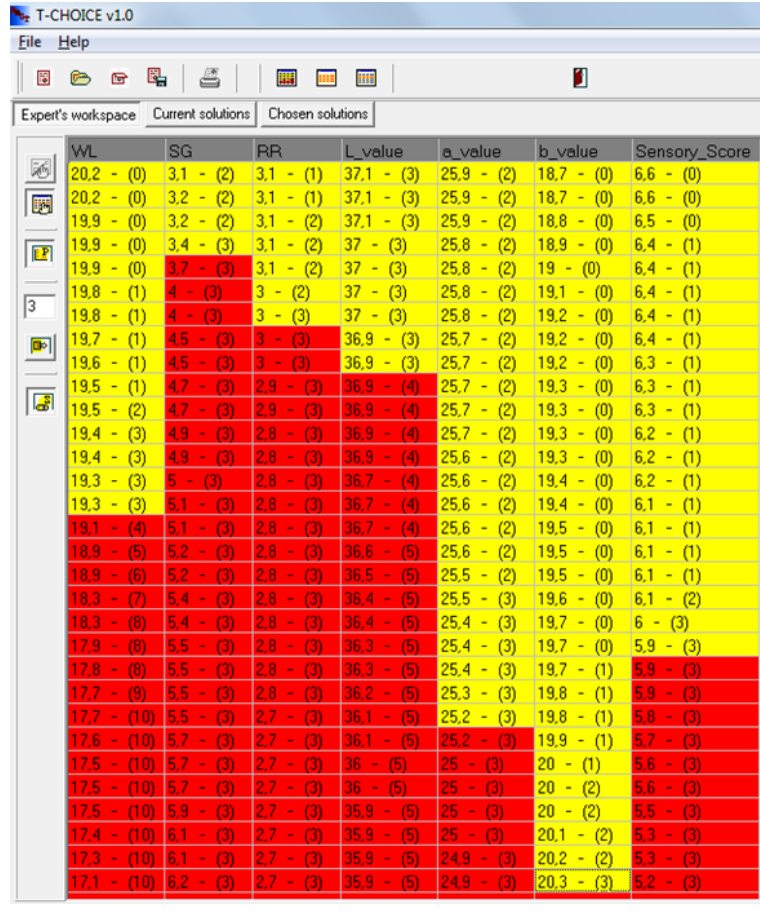

Figure 5: Results after applying the TM method to100 Pareto-optimal frontier points, as computed using the penalty aggregating function (4); the cells marked in yellow are acceptable for each of the criteria whereas those marked in red are not acceptable.

criteria values: $\mathrm{WL}=17.9 \%, \mathrm{SG}=1.8 \%, \mathrm{RR}$ $=3.6, \mathrm{~L}$-value $=37.1$, a-value $=26.5, \mathrm{~b}$-value $=$ 18.3 , Sensory score $=6.2$, is chosen as the final solution to the multi-objective osmotic dehydration decision-making problem, since this alternative has a maximum priority value of 0.1457 . Thus, the solution corresponding to the Paretooptimal point A (with criteria values: WL = $19.0 \%, \mathrm{SG}=2.5 \%, \mathrm{RR}=3.4, \mathrm{~L}$-value $=37.8$, a-value $=25.6$, b-value $=18.1$, Sensory score $=$ $6.9)$ was improved by alternative 3 for the following responses: solute gain, rehydration ratio, and a-value; however, for the two most important criteria, namely sensory score and water loss, alternative 3 demonstrates worse values in comparison to those in point A. Nevertheless, the Paretooptimal solutions, which demonstrate better values for sensory score and water loss, can be computed by repeating the above computations; on 
the other hand, the penalty function (7) can be run. In the Penalty Functions Approach, it is assumed that the expert(s) or decision maker(s) is able to correctly use additional information about the multi-objective decision-making problem at hand; if not, the non-promising solution(s) cannot be implicitly eliminated from the set of Pareto-optimal solutions. Table 13 shows the results after using the penalty function (7) with the following additional constraints: $f_{1}(x) \geq 19.0$ and $f_{7}(x) \geq 7.0$; in other words, only the Paretooptimal solutions that demonstrate better values for the sensory score and water loss criteria will be considered in the decision-making process. In this case, the penalty function (7) was coupled with the linear aggregating function (2), and the following optimization problem was solved by the adaptive random search algorithm:

$$
\sum_{i=1}^{l} \lambda_{i} f_{i}(x)+\Theta_{1}+\Theta_{7} \rightarrow \min _{x \in X}
$$

Table 13 shows the values related to water loss and sensory score that are now better than the corresponding values of point $\mathrm{A}$; however, worse values were obtained for the other responses. The decision-making analysis presented above can be used with the Pareto-optimal alternatives shown in Table 13 in order to choose the best alternative.

All stages of the multi-criteria optimization and decision-making technique as presented in this study and implemented in the software packages developed by Abakarov (2011) can be repeated as many times as necessary in order for the decision maker(s) to obtain the fairest, most consistent, and adequate final compromised solution.

\section{Conclusions}

An alternative technique to solve multi-objective optimization problems arising in food engineering is proposed in this study. This technique has been demonstrated using experimental data obtained on osmotic dehydration of carrot cubes in a sodium chloride solution. Multiple nonlinear regression analysis was performed on a set of experimental data in order to obtain multiobjective functions (responses). The Aggregat- ing Functions Approach, the Adaptive Random Search Algorithm, and the Penalty Functions Approach were used to compute the initial set of the non-dominated or Pareto-optimal solutions. All the aggregating functions presented in this study were implemented simultaneously in order to guarantee a representative subset of the Pareto-optimal solutions. The well-known AHP method and TM were used simultaneously for choosing the best alternative among the computed subset of non-dominated solutions for osmotic dehydration processes. The TM allowed for simplification so that the AHP method could be used in a straightforward manner. The software packages "T-CHOICE" and "MPRIORITY," developed by the authors and used in this study, can significantly simplify a decisionmaking process based on the TM and AHP methods. This technique can be useful to food scientists in research and education, as well as to engineers involved in multi-objective optimization of various food engineering processes.

\section{Acknowledgements}

The author Alik Abakarov wishes to thank the MICINN (Ministerio de Ciencia e Innovación de España) with the project Smart-QC (AGL2008-05267-C03-03), and the TAGRALIAUPM, which is part of the CEI Moncloa Campus.

\section{References}

Abakarov, A. (2011). A multi-criteria decision making approach for food engineering. Proceedings of the 11th International Congress on Engineering and Food (ICEF 11). Paper presented at 11th International Congress on Engineering and Food, held at Athens, Greece, May 22-26, (1525-1526). Athens: Cosmosware.

Abakarov, A, \& Nuñez, M. (2012). Thermal food processing optimization: algorithms and software. Journal of Food Engineering. doi:10.1016/j.jfoodeng.2012.02.013

Abakarov, A, Sushkov, Y, Almonacid, S, \& Simpson, R. (2009). Multiobjective Optimization Approach: Thermal Food Processing. Journal of Food Science, 74(9), E471- 


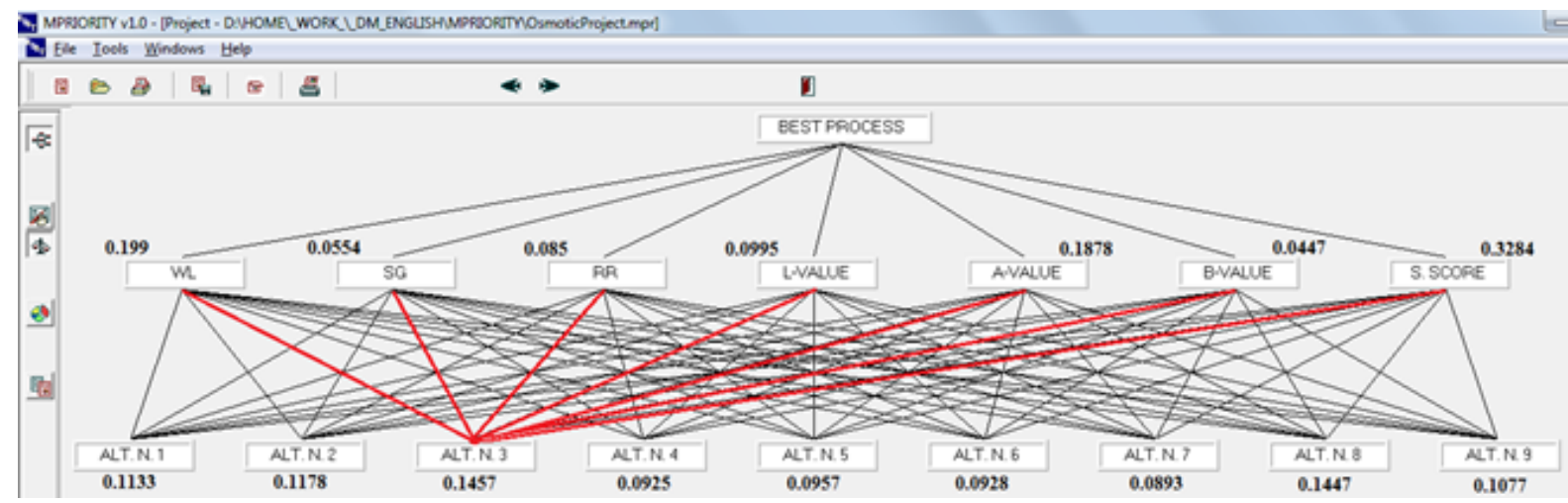

Figure 6: Hierarchy of decisions corresponding to the problem of choosing the most preferred osmotic dehydration process; the main goal (BEST_PROCESS) is set at the top of the hierarchy; the decision alternatives ALT.N.1-ALT.N.9 are at the bottom (see Table 10); the criterion of the decision problem (i.e. water loss (WL), solute gain (SG), rehydration ratio (RR), L-value, a-value, b-value, and sensory score(S.SCORE)) make up the middle of the hierarchy.

Table 10: Reduced set of alternatives obtained through the use of the Tabular Method.

\begin{tabular}{|c|c|c|c|c|c|c|c|}
\hline Alterntive Number & $\begin{array}{c}\text { Water } \\
\text { loss }\end{array}$ & $\begin{array}{c}\text { Solute } \\
\text { gain }\end{array}$ & $\begin{array}{c}\text { Rehydration } \\
\text { ratio }\end{array}$ & $\begin{array}{c}\text { L- } \\
\text { value }\end{array}$ & $\begin{array}{c}\text { a- } \\
\text { value }\end{array}$ & $\begin{array}{c}\text { b- } \\
\text { value }\end{array}$ & $\begin{array}{c}\text { Sensory } \\
\text { score }\end{array}$ \\
\hline 1 & 17.6 & 1.4 & 3.6 & 37.4 & 26.6 & 18.3 & 5.8 \\
\hline 2 & 17.3 & 1.4 & 3.6 & 37.3 & 26.7 & 18.4 & 5.7 \\
\hline 3 & 17.9 & 1.8 & 3.6 & 37.1 & 26.5 & 18.3 & 6.2 \\
\hline 4 & 19.9 & 2.1 & 3.2 & 38.3 & 26.1 & 20.1 & 5.8 \\
\hline 5 & 19.6 & 1.8 & 3.2 & 38.4 & 26.2 & 20.2 & 5.6 \\
\hline 6 & 19.8 & 2.0 & 3.2 & 38.4 & 26.2 & 20.1 & 5.8 \\
\hline 7 & 19.8 & 2.7 & 3.1 & 37.4 & 25.5 & 20.3 & 6.0 \\
\hline 8 & 19.5 & 3.4 & 3.0 & 37.6 & 26.4 & 19.7 & 6.4 \\
\hline 9 & 19.4 & 2.7 & 3.1 & 37.7 & 26.3 & 20.0 & 6.1 \\
\hline
\end{tabular}

Table 11: Results of pair-wise comparison of the main criteria and their computed criteria weights.

\begin{tabular}{|c|c|c|c|c|c|c|c|c|}
\hline Criterion & $\begin{array}{c}\text { Water } \\
\text { loss }\end{array}$ & $\begin{array}{c}\text { Solute } \\
\text { gain }\end{array}$ & $\begin{array}{c}\text { Rehydration } \\
\text { ratio }\end{array}$ & $\begin{array}{c}\text { L- } \\
\text { value }\end{array}$ & $\begin{array}{c}\text { a- } \\
\text { value }\end{array}$ & $\begin{array}{c}\text { b- } \\
\text { value }\end{array}$ & $\begin{array}{c}\text { Sensory } \\
\text { score }\end{array}$ & $\begin{array}{c}\text { Criterion } \\
\text { weight }\end{array}$ \\
\hline Water loss & 1 & 4 & 3 & 2 & 1 & 4 & $1 / 2$ & 0.199 \\
\hline Solute gain & $1 / 4$ & 1 & 1 & $1 / 2$ & $1 / 4$ & 1 & $1 / 5$ & 0.0554 \\
\hline Rehydration ratio & $1 / 3$ & 1 & 1 & 1 & $1 / 2$ & 3 & $1 / 4$ & 0.085 \\
\hline L-value & $1 / 2$ & 2 & 1 & 1 & $1 / 2$ & 3 & $1 / 4$ & 0.0995 \\
\hline a-value & 1 & 4 & 2 & 2 & 1 & 4 & $1 / 2$ & 0.1878 \\
\hline b-value & $1 / 4$ & 1 & $1 / 3$ & $1 / 3$ & $1 / 4$ & 1 & $1 / 5$ & 0.0447 \\
\hline Sensory score & 2 & 5 & 4 & 4 & 2 & 5 & 1 & 0.3284 \\
\hline
\end{tabular}


$18 \mid$ Abakarov et al.

Table 12: Weights for each alternative with respect to each main criterion and the final AHP priorityweights vector.

\begin{tabular}{|c|c|c|c|c|c|c|c|c|}
\hline $\begin{array}{c}\text { Alternative } \\
\text { number }\end{array}$ & $\begin{array}{c}\text { Water } \\
\text { loss }\end{array}$ & $\begin{array}{c}\text { Solute } \\
\text { gain }\end{array}$ & $\begin{array}{c}\text { Rehydration } \\
\text { ratio }\end{array}$ & $\begin{array}{c}\text { L- } \\
\text { value }\end{array}$ & $\begin{array}{c}\text { a- } \\
\text { value }\end{array}$ & $\begin{array}{c}\text { b- } \\
\text { value }\end{array}$ & $\begin{array}{c}\text { Sensory } \\
\text { score }\end{array}$ & $\begin{array}{c}\text { Final priority } \\
\text { vector }\end{array}$ \\
\hline 1 & 0.0291 & 0.2176 & 0.2426 & 0.0375 & 0.2027 & 0.2423 & 0.0675 & 0.1133 \\
\hline 2 & 0.0249 & 0.2213 & 0.2531 & 0.0239 & 0.2828 & 0.2077 & 0.0433 & 0.1178 \\
\hline 3 & 0.0339 & 0.1432 & 0.1878 & 0.0149 & 0.1361 & 0.3506 & 0.2202 & 0.1457 \\
\hline 4 & 0.1776 & 0.0876 & 0.0681 & 0.2090 & 0.0439 & 0.0342 & 0.0486 & 0.0925 \\
\hline 5 & 0.1455 & 0.1486 & 0.0623 & 0.2844 & 0.0619 & 0.0251 & 0.0371 & 0.0957 \\
\hline 6 & 0.1644 & 0.0904 & 0.0695 & 0.2438 & 0.0445 & 0.0293 & 0.0465 & 0.0928 \\
\hline 7 & 0.2238 & 0.0379 & 0.0438 & 0.0415 & 0.0136 & 0.0216 & 0.0953 & 0.0893 \\
\hline 8 & 0.0934 & 0.0195 & 0.0297 & 0.0889 & 0.1405 & 0.0486 & 0.2591 & 0.1447 \\
\hline 9 & 0.1069 & 0.0335 & 0.0427 & 0.0556 & 0.0734 & 0.0399 & 0.1820 & 0.1077 \\
\hline
\end{tabular}

Table 13: Results after using the penalty function (13).

\begin{tabular}{|c|c|c|c|c|c|c|c|}
\hline $\begin{array}{c}\text { Number of } \\
\text { solution }\end{array}$ & $\begin{array}{c}\text { Water } \\
\text { loss }\end{array}$ & $\begin{array}{c}\text { Solute } \\
\text { gain }\end{array}$ & $\begin{array}{c}\text { Rehydration } \\
\text { ratio }\end{array}$ & $\begin{array}{c}\text { L- } \\
\text { value }\end{array}$ & $\begin{array}{c}\text { a- } \\
\text { value }\end{array}$ & $\begin{array}{c}\text { b- } \\
\text { value }\end{array}$ & $\begin{array}{c}\text { Sensory } \\
\text { score }\end{array}$ \\
\hline 1 & 20.3 & 3.9 & 3.1 & 36.3 & 25.5 & 17.8 & 7.5 \\
\hline 2 & 21.8 & 6.1 & 2.7 & 35.8 & 25.5 & 17.4 & 7.5 \\
\hline 3 & 20.7 & 4.4 & 3.0 & 36.2 & 25.4 & 17.7 & 7.7 \\
\hline 4 & 21.5 & 6.2 & 2.6 & 35.4 & 25.9 & 17.4 & 7.3 \\
\hline 5 & 19.9 & 3.5 & 3.2 & 36.5 & 25.6 & 17.9 & 7.4 \\
\hline 6 & 21.2 & 5.1 & 2.9 & 36.0 & 25.4 & 17.6 & 7.7 \\
\hline 7 & 20.9 & 5.6 & 2.7 & 35.2 & 26.1 & 17.4 & 7.5 \\
\hline 8 & 19.7 & 3.2 & 3.2 & 36.6 & 25.7 & 17.9 & 7.3 \\
\hline 9 & 21.0 & 4.9 & 2.9 & 36.0 & 25.4 & 17.6 & 7.7 \\
\hline 10 & 21.8 & 6.2 & 2.7 & 35.8 & 25.6 & 17.4 & 7.4 \\
\hline 11 & 19.2 & 2.8 & 3.3 & 36.8 & 25.8 & 18.0 & 7.0 \\
\hline 12 & 21.9 & 6.3 & 2.7 & 35.7 & 25.6 & 17.4 & 7.4 \\
\hline
\end{tabular}


Multi-criteria optimization for food engineering |19

E487. doi:10.1111/j.1750-3841.2009.01348. $\mathrm{x}$

Azarpazhooh, E., \& Ramaswamy, H. S. (2012). Modeling and Optimization of Microwave Osmotic Dehydration of Apple Cylinders Under Continuous-Flow Spray Mode Processing Conditions. Food and Bioprocess Technology, 5(5), 1486-1501. doi:10.1007/ s11947-010-0471-9

Barbosa-Cánovas, G., \& Vega-Mercado, H. (1996). Physical, chemical, and microbiological characteristics of dehydrated foods. In: Dehydration of foods, BarbosaCánovas, G.V. \& Vega-Mercado, H., Eds., New York, USA, Chapman \& Hall, International Thompson Publishing, pp. 29-99.

Belton, V, \& Stewart, T. (2002). Multiple criteria decision analysis: an integrated approach. Kluwer Academic Pub. Retrieved from http://books.google.pt/books?id= mxNsRnNkL1AC

Beuthe, M, \& Scannella, G. (2001). Comparative analysis of UTA multicriteria methods. European Journal of Operational Research, 130(2), 246-262. doi:10 . 1016 / S0377 2217(00)00042-4

Bevilacqua, M, D'Amore, A, \& Polonara, F. (2004). A multi-criteria decision approach to choosing the optimal blanchingfreezing system. Journal of Food Engineering, 63(3), 253-263. doi:10.1016/j . jfoodeng.2003.07.007

Brockhoff, D., \& Zitzler, E. (2009). Objective Reduction in Evolutionary Multiobjective Optimization: Theory and Applications. Evolutionary Computation, 17(2), 135-166. doi:10.1162/evco.2009.17.2.135

Carmone, F., Kara, A, \& Zanakis, S. (1997). A Monte Carlo investigation of incomplete pairwise comparison matrices in AHP. European Journal of Operational Research, 102(3), 538-553. doi:10 . 1016 / S0377 2217(96)00250-0

Costa, C., \& Chagas, M. (2004). A career choice problem: An example of how to use MACBETH to build a quantitative value model based on qualitative value judgments. European Journal of Operational Research, 153(2), 323-331. 12th Mini Euro Confer- ence, BRUSSELS, BELGIUM, APR 02-05, 2002. doi:10.1016/S0377-2217(03)00155-3

Deb, K. (2001). Multi-objective optimization using evolutionary algorithms. WileyInterscience series in systems and optimization. John Wiley \& Sons. Retrieved from http://books.google.pt/books?id= iwNRAAAAMAAJ

Deb, K, \& Saxena, D. (2006). Searching for Pareto-optimal solutions through dimensionality reduction for certain largedimensional multi-objective optimization problems. Proc. of 2006 IEEE Congress on Evolutionary Computation, pp. 33533360, Vancouver, July 16-21, Piscataway, NJ: IEEE Press

Del Castillo, E. (2007). Process optimization: a statistical approach. Springer,New York.

Derringer, G, \& Suich, R. (1980). Simultaneousoptimization of Several Response Variables. Journal of Food Engineering, 12(4), 214-219.

Derringer, G. (1994). A Balancing Act - Optimizing a Products Properties. Quality Progress, 27(6), 51-58.

Erdogdu, F. (2003). Complex method for nonlinear constrained multi-criteria (multiobjective function) optimization of thermal processing. Journal of Food Engineering, 26(4), 357-375. doi:10.1111/j.1745-4530. 2003.tb00607.x

Optimization in Food Engineering. (2009). In Erdogdu, F (Ed.), Optimization in Food Engineering (1-777). Contemporary Food Engineering.

Eren, I., \& Kaymak-Ertekin, F. (2007). Optimization of osmotic dehydration of potato using response surface methodology. Journal of Food Engineering, 79(1), 344-352. doi:10.1016/j.jfoodeng.2006.01.069

Multiple Criteria Decision Analysis: State of the Art Surveys. (2005). In J Figueira, S Greco \& M Ehrgott (Eds.), Multiple Criteria Decision Analysis: State of the Art Surveys (Vol. 78, 1-1085). International Series in Operations Research \& Management Science. doi:10.1007/b100605

Fogliatto, F, \& Albin, S. (2003). An AHP-based procedure for sensory data collection and analysis in quality and reliability applica- 
tions. Food Quality and Preference, 14(56), 375-385.

Goñi, S, \& Salvadori, V. (2011). Multi-objective optimization of beef roasting. In Proceedings of the 11th International Congress on Engineering and Food. Paper presented at 11th International Congress on Engineering and Food, held at Vancouver, Canada, 16-21 July (p.1425) Vol.3, pp. 1425. Athens, Greece: Cosmosware.

Goñi, S. M., \& Salvadori, V. O. (2012). Modelbased multi-objective optimization of beef roasting. Journal of Food Engineering, 111(1), 92-101. doi:10.1016/j.jfoodeng . 2012.01.022

Grandzol, J. (2005). Improving the faculty selection process in higher education: a case for the analytic hierarchy process. IR Applications, (6), 1-13.

Hadiyanto, H, Boom, R, Van Straten, G, Van Boxtel, A, \& Esveld, D. (2009). Multiobjective Optimization to Improve the Product Range of Baking Systems. Journal of Food Engineering, 32(5), 709-729. doi:10.1111/j.1745-4530.2008.00240.x

Joshua, D, \& David, D. (2000). Approximating the Nondominated Front Using the Pareto Archived Evolution Strategy. Evolutionary Computation, 8(2), 149-172. doi:10.1162/ 106365600568167

Keeney, R, \& Raiffa, H. (1993). Decisions with Multiple Objectives, Preferences and Value Trade Offs. Cambridge, UK: Cambridge University Press.

Kiranoudis, C., \& Markatos, N. (2000). Pareto design of conveyor-belt dryers. Journal of Food Engineering, 46(3), 145-155. doi:10. 1016/S0260-8774(00)00060-1

Marler, R., \& Arora, J. (2004). Survey of multiobjective optimization methods for engineering. Structural and Multidisciplinary Optimization, 26(6), 369-395. doi:10.1007/ s00158-003-0368-6

Mehnen, J, \& Trautmann, H. (2006). Integration of Expert's Preferences in Pareto Optimization by Desirability Function Techniques. In: Proceedings of the 5th CIRP International Seminar on Intelligent Computation in Manufacturing Engineering (CIRP ICME '06). Paper presented at 5th
CIRP International Seminar on Intelligent Computation in Manufacturing Engineering, held at Ischia, Italy, (293-298). Italy: R. Teti (ed.)

Miller, G. (1956). The Magical Number 7, Plus or Minus 2 - Some Limits on our Capacity for Processing Information. Psychological Review, 63(2), 81-97. doi:10.1037/h0043158

Noshad, M, Mohebbi, M, Shahidi, F, \& Mortazavi, S. (2012). Multi-Objective Optimization of Osmotic-Ultrasonic Pretreatments and Hot-Air Drying of Quince Using Response Surface Methodology. Food Bioprocess Technology, 5(6), 2098-2110. doi:10.1007/s11947-011-0577-8

Purshouse, R., \& Fleming, P. (2003). Conflict, harmony, and independence: Relationships in evolutionary multi-criterion optimisation. In Fonseca, CM and Fleming, PJ and Zitzler, E and Deb, K and Thiele, L (Ed.), Evolutionary Multi-criterion Optimization, Proceedings (Vol. 2632, 16-30). LECTURE NOTES IN COMPUTER SCIENCE. 2nd International Conference on Evolutionary Multi-Criterion Optimization (EMO 2001), UNIV ALGARVE, FARO, PORTUGAL, APR 08-11, 2003.

Saaty, T. (1990). How to Make a Decision The Analytic Hierarchy Process. European Journal of Operational Research, 48(1), 926. doi:10.1016/0377-2217(90)90057-I

Sendín, J. O. H., Alonso, A. A., \& Banga, J. R. (2010). Efficient and robust multiobjective optimization of food processing: A novel approach with application to thermal sterilization. Journal of Food Engineering, 98(3), 317-324. doi:10.1016/j . jfoodeng.2010.01.007

Seng, C, \& Rangaiah, G. (2008). Multi-Objective Optimization in Food Engineering. In F Erdogdu (Ed.), Optimization in Food Engineering (153-178). Contemporary Food Engineering.

Sharma, S, Rangaiah, G., \& Cheah, K. (2012). Multi-objective optimization using MS Excel with an application to design of a falling-film evaporator system. Food and Bioproducts Processing, 90(C2), 123-134. doi:10.1016/j.fbp.2011.02.005 
Siinivas, N, \& Deb, K. (1994). Multiobjective Optimization Using Nondominated Sorting in Genetic Algorithms. Evolutionary Computation, 2(3), 221-248.

Singh, B, Paramjit, S, Nanda, V, \& Bera, M. (2008). Optimization of Osmotic Dehydration Process of Carrot Cubes in Sodium Chloride Solution. International Journal of Food Engineering, 4(2). doi:10.2202/15563758.1141

Statnikov, R, \& Matusov, J. (1995). Multicriteria Optimization and Engineering. New York: Chapman \& Hall.

Statnikov, R, Bordetsky, A, \& Statnikov, A. (2005). Multicriteria analysis of real-life engineering optimization problems: statement and solution. Nonlinear Analysistheory Methods \& Applications, 63(5-7), E685-E696. doi:10.1016/j.na.2005.01.028

Steuer, R. (1985). Multiple criteria optimization: theory, computation and application. New York: JohnWiley\& Sons.

Sushkov, Y. (1984). Multi-objective optimization of multi-regime systems. Digital System Architecture. (21-24). Moscow: Moscow State University.

Tan, K, Khor, E, \& Lee, T. (2005). Multiobjective evolutionary algorithms and applications. Advanced Information and Knowledge Processing. Springer. Retrieved from http : / / books . google . pt / books ? id = Ind8fjqYg94C

Thakur, M, Wang, L, \& Hurburgh, C. (2010). A multi-objective optimization approach to balancing cost and traceability in bulk grain handling. Journal of Food Engineering, 101(2), 193-200. doi:10 . 1016 / j . jfoodeng.2010.07.001

Treitz, M, Schollenberger, I, Schrader, B, Geldermann, J, \& Rentz, O. (2005). Multi-criteria decision support for integrated technique assessment. RadTech Europe 2005, Conference Proceeding, Vol. II. 2005, pp 155-160, edited and published by RadTech Europe.

Vansnick, J. (1986). On the Problem of Weights in Multiple Criteria Decision-Making (the Noncompensatory Approach). European Journal of Operational Research, 24(2), 288-294. doi:10.1016/0377-2217(86)900512
Vassilev, V, Genova, K, \& Vassileva, M. (2005). A Brief Survey of Multicriteria Decision Making Methods and Software Systems. Cybernetics and Information Technologies, 5(1), 3-14.

Von Winterfeldt, D, \& Edwards, W. (1986). Decision Analysis and Behavioral Research. London: Cambridge University Press.

Xu, Shiying, Xiufang, C, \& Da-Wen, S. (2001). Preservation of kiwifruit coated with an edible film at ambient temperature. Journal of Food Engineering, 50(4), 211-216. doi:10.1016/S0260-8774(01)00022-X

Zhigljavsky, A, \& Zilinskas, A. (2008). Stochastic Global Optimization. In Stochastic Global Optimization (Vol. 1, 1-262). Springer Series in Optimization and Its Applications.

Zitzler, E, \& Thiele, L. (1999). Multiobjective evolutionary algorithms: A comparative case study and the Strength Pareto approach. IEEE Transactions on Evolutionary Computation, 3(4), 257-271. doi:10. 1109/4235.797969 